Vooren, A. P. \& D. M. J. Offermans, 1985. An ultralight aircraft for low-cost, large-scale stereoscopic aerial photographs. Biotropica 17: 84-88.

Zimmermann, M.H., 1983. Xylem structure and the ascent of sap. Springer, Heidelberg, 143 pp.

This synopsis is based on a M. Sc. thesis by Don M. J. Offermans entitled 'Field and aerial observations on Piptadeniastrum africanum (Hook. f.) Brenan, with special reference to ageing', Department of Silviculture, Agricultural University, Wageningen, 1985. $x+83$ pp., 26 figs., 4 tables, 71 refs., 6 appendices.

Available as paper copy (order R058P, $f 20$ including postage) or microfiche (order R058M, f 12.50 including postage) at: NARD, c/o Pudoc, P.O. Box 4, 6700 AA Wageningen, Netherlands (telex 45015 blhwg nl).

\title{
Measured and simulated drought stress effects on daily shoot and root growth rates of soybean*
}

Gerrit Hoogenboom ${ }^{1}$, M. G. Huck ${ }^{2}$ and Curt M. Peterson ${ }^{3}$ ('Department of Agricultural Engineering, University of Florida, Gainesville, FL 32611, USA; ${ }^{2}$ USDAARS, Department of Agronomy, University of Illinois, Urbana, IL 61801, USA; ${ }^{3}$ Department of Botany, Plant Pathology and Microbiology, Alabama Agricultural Experiment Station, Auburn University, Auburn, AL 36849, USA)

Received 29 May 1986; accepted 30 July 1986

\begin{abstract}
The effects of drought stress upon daily shoot and root growth rates of soybean (Glycine max [L.] Merr. 'Braxton') were investigated in experimental studies at the Auburn rhizotron, and in computer simulation studies. Plants were grown in loamy sand and received only rainfall (nonirrigated, NI), or rainfall plus additional irrigation (IR) over the entire growing season. Shoot and root growth followed characteristic exponential growth curves during early vegetative development when no moisture stress was evident. When water stress was imposed during the later stages of vegetative growth or early reproductive development, an increase in root growth rate and a decrease in shoot growth rate was observed in the NI treatment. However, after periods of rainfall, the soil profile was rewet and shoot growth of NI plants was optimal. Thus, long term effects of water stress on final shoot size were not evident. Stimulation of root growth during water stress periods was less pronounced after plants had reached the pod development stage. In ad-
\end{abstract}

\footnotetext{
* Alabama Agricultural Experiment Station Paper 6-861010
} 
dition to experimental studies, a dynamic root-growth simulation model, ROOTSIMU, was expanded and calibrated using the 1981 experimental data. The model provided an excellent way to summarize the experimental data and provided a theoretical explanation for plant processes which occur during periods of water stress, namely that the fraction of dry matter partitioned into the roots increases with longer and more severe stress periods. This changes the root/shoot ratio which results from the formation of a larger root and a smaller shoot system.

Key words: Glycine max (L.) Merr., root growth, shoot growth, drought stress, computer model.

Introduction. In earlier investigations at the Auburn rhizotron it was reported that soybean yield was significantly reduced when plants were grown under droughtstress conditions (Huck et al., 1983). Conversely, it was observed that there were no significant differences between yield of irrigated and nonirrigated plants during relatively wet years (Huck et al., 1986). Therefore this study was performed to investigate in greater detail the effect of drought stress on growth rates of shoot and root systems during the entire growing season, and especially to determine how shoot and root growth were affected during periods of drought stress.

Simultaneously, a dynamic root-growth and water uptake simulation model ROOTSIMU, originally developed by Huck \& Hillel (1983), was expanded and improved. The model calculates a functional growth balance between the shoot and root system of a plant based upon its canopy water potential. This is in turn is affected by $\psi_{\text {soil }}$ and transpiration and water uptake rates. The model was used to summarize the experimental observations at the rhizotron and to provide a mechanistic and theoretical explanation of the effects of drought stress on shoot-root relationships.

Materials and methods. Soybean plants (Glycine max [L.] Merr. 'Braxton') were grown in loamy sand (fine-loamy, siliceous, thermic Plinthic Paleudult) in compartments of the Auburn rhizotron during the 1981, 1982, and 1983 growing seasons. Two treatments were applied: nonirrigation or rainfall only (NI) and rainfall with additional irrigation (IR). Water was added by irrigation whenever soil-water potential $\left(\psi_{\text {soil }}\right)$ fell below $-15 \mathrm{kPa}$ as measured by tensiometers at a depth of $0.4-\mathrm{m}$. $\psi_{\text {soil }}$ was recorded daily. At selected time intervals, leaf water potentials $\left(\psi_{\text {leaf }}\right)$ were measured diurnally with a pressure chamber. Both shoot and root growth were determined by measuring morphological features of the plant. Shoot growth was measured by recording, at 2- to 4-day intervals, height of the mainstem and length of the axillary branches, number of leaves on the mainstem and branches, and length of the terminal leaflet at all mainstem nodes. Root growth was measured by recording, at the same time intervals, the increase in length of newly formed roots visible through rhizotron windows. Because of the experimental design of the rhizotron, biomass samples only could be taken at final harvest.

In the model ROOTSIMU, the shoot growth section was extended, and a canopy-photosynthesis section was added. Root-growth and water-uptake sections also were refined. Input conditions for the model were changed so that daily observed 
weather data, e.g. minimum and maximum soil and air temperatures and daily totals of radiation, rainfall and open pan evaporation, could be used as a driver for the model instead of previously used sine-wave generators. Experimental data and constants published in the literature were used to define plant parameters. The results from soil samples taken in the bins of the rhizotron and analyzed in the laboratory were used to define soil parameters and the water retention curve. The model, originally developed in the simulation language CSMP, was run for a 100-day period on a mainframe computer.

Results and discussion. During early stages of vegetative growth (e.g., first 6 mainstem nodes) no influence of drought stress upon shoot and root development was observed. However, as canopy size increased, plants were more susceptible to the effects of drought stress. Initially, roots grew in the upper soil layers; but after plants extracted most of the water from these layers, both $\psi_{\text {soil }}$ and root growth decreased in the upper layers and root growth increased in the deeper, wetter soil layers. During periods with no rainfall, $\psi_{\text {soil }}$ for the NI treatment decreased more rapidly than for the IR treatment, causing a decrease in shoot growth rate (e.g., leaf expansion and mainstem elongation) and an increase in root growth rates. After periods of rainfall, which rewet the soil profile, root growth rate with the NI treatment was reduced and shoot growth rate increased. In some cases, the shoot growth rate of NI plants was higher during periods of rainfall than the shoot growth rate of IR plants. During most drought periods, $\psi_{\text {soil }}$ at a $0.4-\mathrm{m}$ depth in the IR treatment also decreased causing an increase in root growth rate. When rain or irrigation water rewet the upper part of the soil profile, root growth rate in that region decreased to its normal level. Both shoot and root senescence were enhanced during periods of water stress and shoot and root growth ceased completely during pod development and early seedfill. Because vegetative growth of NI plants recovered after periods of water stress, total leaf area, plant height, and total number of nodes were not significantly $(P>0.05)$ different for the IR and NI treatments at the end of the growing season. Similar recoveries of drought-stressed plants after periods of heavy rainfall were observed by Cure et al. (1983).

In the simulation trial runs, using 1981 weather data as driving functions for the model, we found that the differences between plants given the IR and NI treatment were similar to those observed in previously reported rhizotron and field experiments. Of all three growing seasons, 1981 was a very dry year with several stress periods occurring early in the growing season. During these periods both simulated $\psi_{\text {soil }}$ and canopy water potential were lower for the NI than the IR treatment. On certain days, partial stomatal closure and a significant decrease in photosynthetic rates during the middle of the day for simulated NI plants were predicted, similar to that reported in field experiments. At the same time, the simulation model predicted that root growth would decrease in the upper soil layers and increase in the wetter, deeper, soil layers. Also, after periods of rainfall, root growth decreased and shoot growth increased. Because the model ROOTSIMU was originally developed to simulate root-shoot partitioning and growth, simulations were run only until vegetative growth had ceased completely (i.e., about 100 days after planting). 


\section{G. HOOGENBOOM ET AL.}

The small time steps used in the model (e.g. one hour or less) made it possible to observe instantaneous responses in simulated plant growth, as might have occurred in plants grown under drought conditions in field experiments.

Conclusions. Shoot and root growth were not significantly different between IR and NI treatments during relatively wet periods. Differences were noted when $\psi_{\text {soil }}$ at the $0.4-\mathrm{m}$ depth dropped below $-15 \mathrm{kPa}$. Then, drought stress was observed, shoot growth slowed, and root growth increased in the NI treatment. After rainfall, root growth slowed again and shoot growth increased. Vegetative growth ceased completely during the seed-filling stage. Final shoot size of NI and IR plants was not significantly different. However, significant differences by treatment were observed for the final size of the two root systems and the distribution of roots within the soil layers.

Revision of the model ROOTSIMU allowed comparison between simulation predictions and experimental data using the observed weather data as a driver for the model. The revised model gave similar differences in shoot and root growth rates between IR and NI treated plants as found in the rhizotron experiments, but absolute values were not the same because of differences in measurement procedures. However, the model showed that it can be a very useful tool in helping to understand the complexity of interactions which occur in both the shoot and root system of the plant during periods of drought stress.

\section{References}

Cure, J. D., C. D. Raper, R. P. Patterson \& W. A. Jackson, 1983. Water stress recovery in soybeans as affected by photoperiod during seed development. Crop Science 23: 110-115.

Huck, M. G. \& D. Hillel, 1983. A model of root growth and water uptake accounting for photosynthesis, respiration, transpiration, and soil hydraulics. In: D. Hillel (Ed.), Advances in irrigation, Vol. 2, p. 273-333. Academic Press, New York.

Huck, M. G., K. Ishihara, C. M. Peterson \& T. Ushijima, 1983. Soybean adaptation to water stress at selected stages of growth. Plant Physiology 73: 422-427.

Huck, M. G., C. M. Peterson, G. Hoogenboom \& C. D. Busch, 1986. Distribution of dry matter between shoots and roots of irrigated and nonirrigated determinate soybeans. Agronomy Journal 78 : 807-813.

This synopsis is based on a doctoral thesis entitled 'Shoot and root growth of soybean (Glycine max [L.] Merr.) under water stress: experimental and simulation studies', Auburn University, Auburn, Alabama, USA, 1985. 277 pp., 51 figs., 9 tables, 3 appendices, 159 refs. English.

Available as paper copy (order R059P, $f 75$ including postage) or microfiche (order R059M, $f 22.50$ including postage) at: NARD, clo Pudoc, P.O. Box 4, 6700 AA Wageningen, Netherlands (telex 45015 blhwg $\mathrm{hl}$ ). 